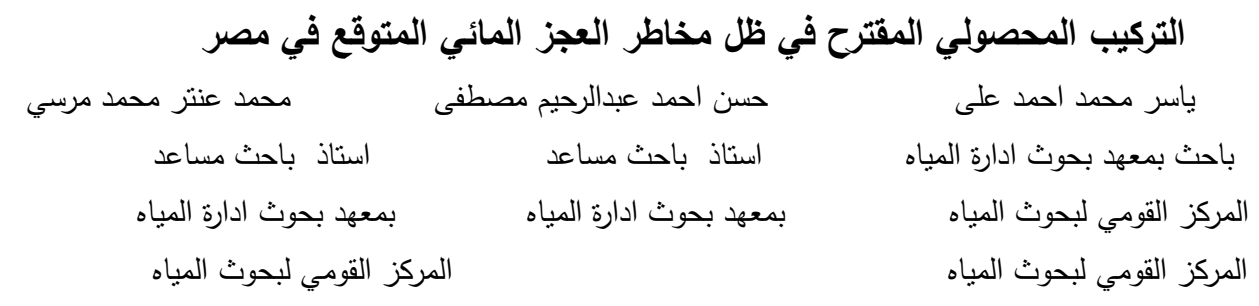

مقدمة:

تبذل دول العالم جهوداً عديدة من اجل توفير المياه المطلوبة والعمل على حمايتها سواء من مخاطر الجفاف أو الفيضانات بالإضافة لبذل جهود كبيرة

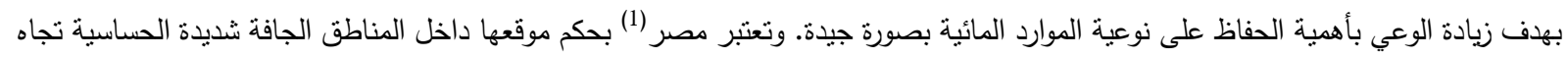
مواردها المائية المددودة والني نأني من خارج حدودها الجغرافية حيث تعتد على نهر النيل كمصدر رئيسي للمياه والذي نقدر حصنه بنحئ

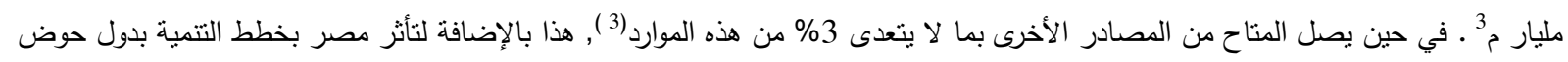

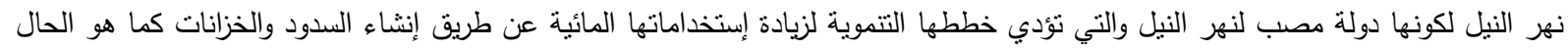

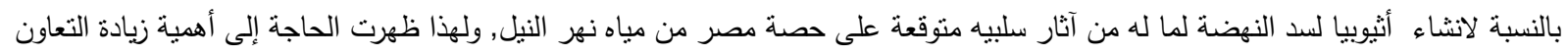

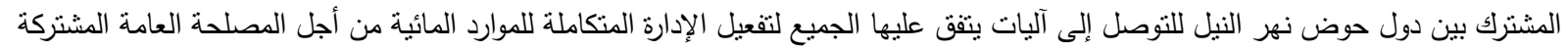

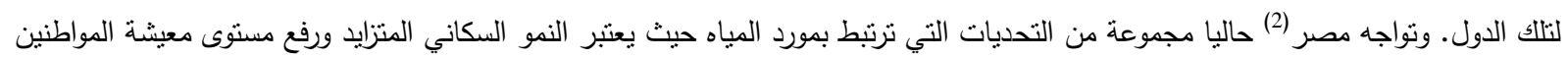
من التحديات الرئيسية التي تثودي إلى زيادة الإحتياجات المائية لمختلف القطاعات المستهلكة لمورد المياه. ويعثبر النمو السكاني أحد الأسباب الرئيسية

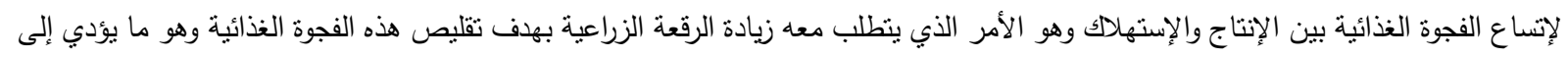
زيادة الإحتياجات المائية للازراعة, كما يؤدي النمو السكاني أيضا إلى إنشاء المدن السكنية والصناعية الجديدة التي تنطلب مزيد من الإحتياجات المائية لقطاعى الثرب والصناعة.

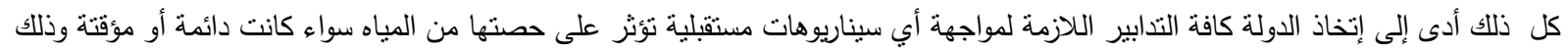

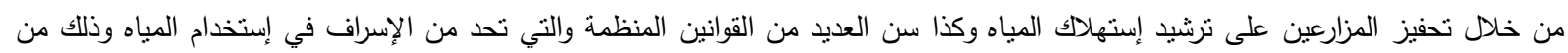

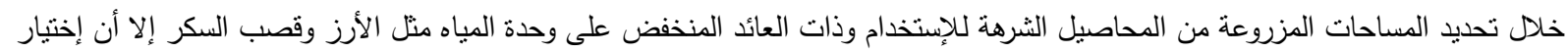

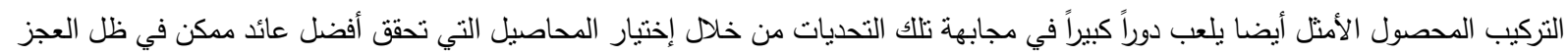

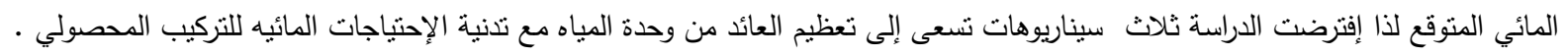

مشكلة البحث:

تعتبر الموارد المائية المتاحة حالياً فى مصر لا تكفى للتوسع الزراعى الأفقى المستقبلى فى ظل الانماط الاستهلاكية لاستخدام تلك الموارد لذا فان

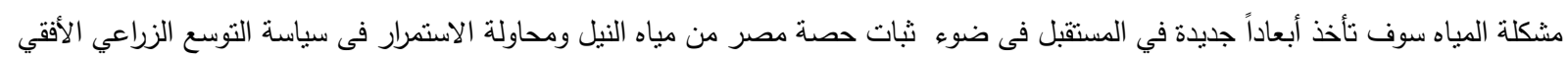

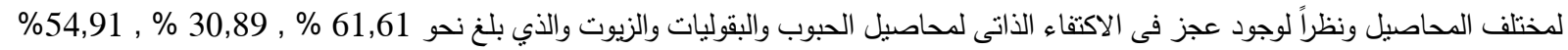

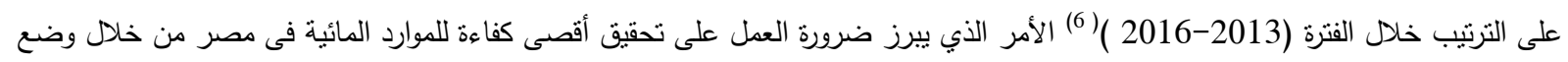

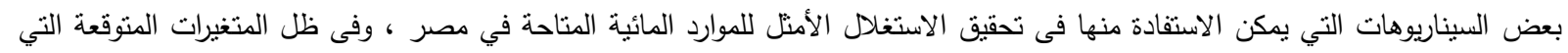

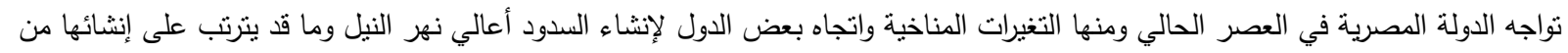

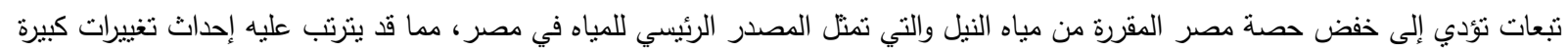

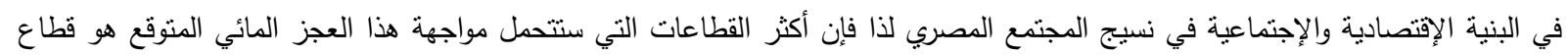

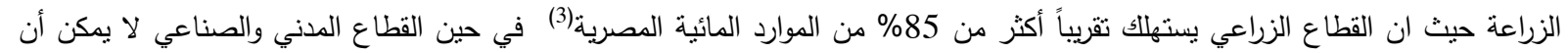
يتحمل إلا نسبة ضئيلة جدا من هذا العجز ومن خلال رفع الوعي وترشيد استخدام المياه.

هدف البحث:

يتمثل الهدف من الدراسة في إلقاء الضوء على الإجراءات والتدابير اللازمة للحد من الآثار المتوقعة نتيجة احتمال تعرض مصر لعجز في الموارد

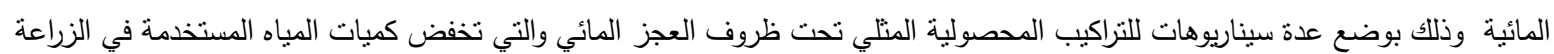
مع تحقيق أعلى إنتاج وعائد ممكن لوحدة المياه وذلك. 
5-الطريقة البحثية ومصادر البيانات:

إعتمدت الدراسة على أساليب التحليل الإحصائي والوصفي والكمي منل أسلوب برمجة الأهدافئ ومات والتي تعد من نماذج بحوث العمليات المستخدمة في مجال التخطيط الاقتصادي وتوجيه الموارد، وذلك من أجل تحقيق التراكيب المحصولية المتلى التي تعظم صافي العائد من الأنشطة الزراعية

في ظل محدودية الموارد المائية. واعتمدت الدراسة على البيانات الثانوية المنشورة وغير المنشورة والني أمكن الحصول عليها من بعض الوزارات والمنظمات والهيئات, منل وزارة الموارد المائية والري والجهاز المركزي للتعبئة العامة والإحصاء, قطاع الشئون الإقتصادية بوزارة الزراعة, وكذلك الأبحاث والدراسات المتعلقة بموضوع الدراسة .

\section{- - أسلوب برمجة الأهداف Goal Programming. -}

يعتبر أسلوب برمجة الأهداف امتداد لأسلوب البرمجة الخطية ، حيث يمكن من خلاله التعامل مع المشاكل ذات الأهداف المتعددة أو المتعارضة

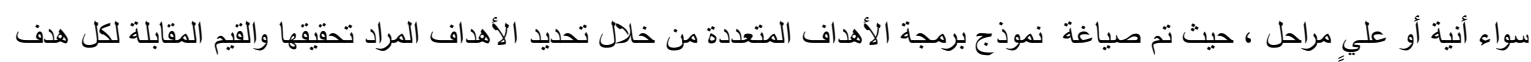

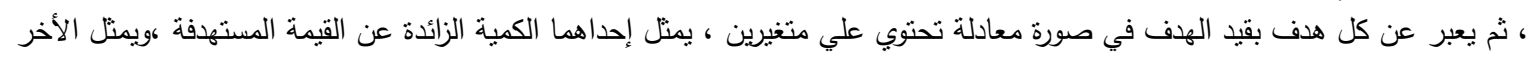

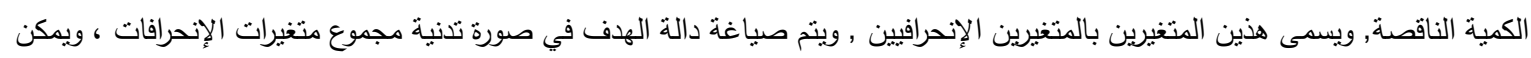
تقدير معامل يقابل كل هدف يعرف باسم "معامل أولوية" وهو يعكس درجة تفضيل متخذ القرار للهدف (7). -

تمثل صياغة نموذج البرمجه اهم مرحله لبرمجه الاهداف ایى التعبير عن علاقات واقعية بعلاقات رياضية مفترضة ومبنية علي دراسة الواقع وتحليله من أجل صياغة نموذج البرمجة.

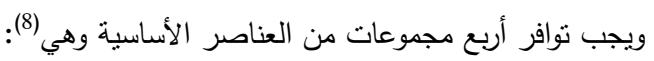

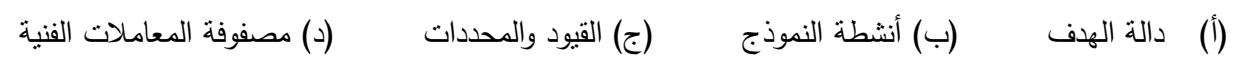

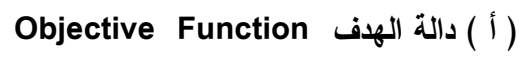

الهدف الرئيسـي لهذه الدالة هو ترشـيد اســتخدام الموارد المائية المتاحة من خلال خفض كميات مياه الري المســخدمة في ري المحاصـيل المختلفة ولتحقيق هذا الهدف تم التركيز على تعظيم صـــافي عائد وحدة مياه الري (جنية/م 3 ) حيث يأخذ هذا البديل في الإعنبار كلاً من تعظيم عائد وحدة الإنتاج الزراعي وتدنية الإحتياجات المائية المستخدمة في الري لكافة المحاصيل الداخلة في النموذج. $\operatorname{Max} z=\Sigma_{I}\left(P_{J K} Y_{J K}-C_{J K}\right) X_{J K}-\Sigma V_{J K}$

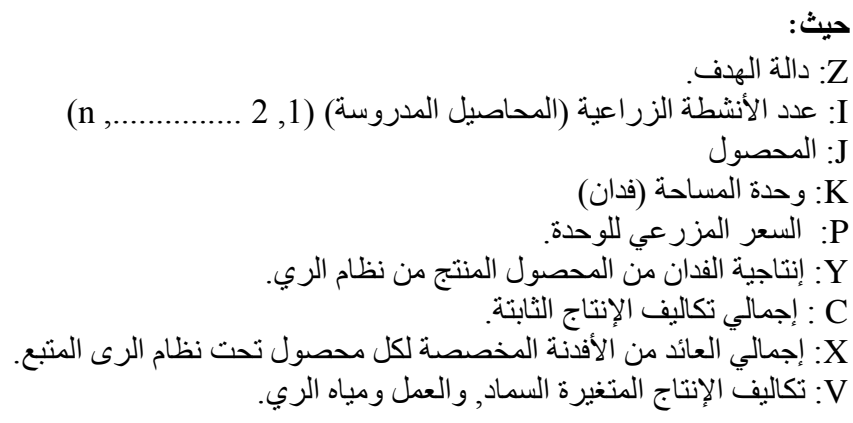

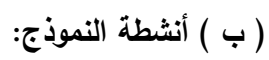

تتضمن الأنشطة الإنتاجية للنموذج إختيار 28 محصولاً تمثل أهم المحاصيل المزروعة فى مصر ويحتوي على أهم محاصيل الخضر والمحاصيل

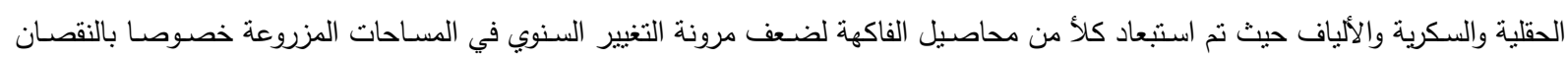
وكذلك محاصيل الخضر والحقلية غير المؤثرة والتي تزرع بمساحات صغيرة كما هو موضح بالجدول رقم (1).

( ) ( ) ( القيود و المحددات

تم تعظيم دالة الهدف لنموذج الدراسة وفقاً للعديد من المحددات يمكن تصنيفها إلى نوعين هما محددات مورديه ومحددات تتظيميه وتشمل: المحددات

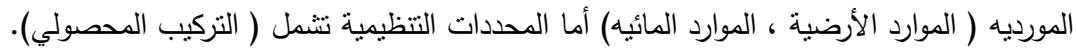


جدول رقم 1. مساحة محاصيل أنشطة النموذج خلال الفترة من (2013 - 2017).

\begin{tabular}{|c|c|c|c|c|c|c|c|}
\hline \multirow{2}{*}{ الأهمية النسبية لكل } & \multicolumn{6}{|c|}{ مساحة المحاصيل بالألف فدان } & \multirow[b]{2}{*}{ المحصول } \\
\hline & المتوسط & 2017 & 2016 & 2015 & 2014 & 2013 & \\
\hline 53,88 & 3429,8 & 3566,2 & 3462,3 & 3305,6 & 3413,4 & 3401,5 & القـــح \\
\hline 2,23 & 142,0 & 139,1 & 138,3 & 140,2 & 143,8 & 148,4 & الثــعير \\
\hline 19,48 & 1240,1 & 1234,3 & 1236,4 & 1251,5 & 1234,2 & 1244,0 & البرسيم المستديم \\
\hline 5,28 & 335,8 & 343,4 & 341,2 & 332,3 & 319,4 & 342,9 & البرسيم التحريش \\
\hline 1,57 & 100,1 & 105,9 & 89,7 & 92,2 & 96,4 & 116,2 & الفول البلدي \\
\hline 0,02 & 1,1 & 1,6 & 1,3 & 0,8 & 1,0 & 0,9 & العــس " \\
\hline 0,02 & 1,4 & 1,6 & 1,3 & 1,2 & 1,5 & 1,4 & الحمص \\
\hline 7,96 & 506,6 & 512,1 & 526,6 & 529,6 & 504,3 & 460,5 & بنجر السـكر \\
\hline 0,09 & 5,9 & 6,4 & 6,1 & 6,7 & 6,9 & 3,4 & الكـتان \\
\hline 2,48 & 158,1 & 171,1 & 166,8 & 167,8 & 160,6 & 124,2 & البصــل \\
\hline 0,41 & 26,1 & 32,4 & 31,2 & 18,4 & 26,2 & 22,2 & الثوم \\
\hline 3,06 & 194,8 & 154,5 & 176,5 & 251,8 & 195,5 & 195,8 & طمــاطم \\
\hline 3,51 & 223,6 & 197,8 & 203,9 & 293,4 & 221,2 & 201,7 & بطاطس \\
\hline 100,00 & 6365,3 & 6466,4 & 6381,6 & 6391,5 & 6324,4 & 6262,8 & جملة الثتوي \\
\hline 38,22 & 2195,9 & 2328,5 & 2287,6 & 2293,9 & 1986,5 & 2083,0 & الذرة الثـاميـــــة \\
\hline 6,04 & 347,3 & 381,7 & 312,9 & 354,5 & 352,1 & 335,2 & الذرة الرفيعـــــــة \\
\hline 24,64 & 1415,8 & 1340,2 & 1472,4 & 1483,1 & 1363,8 & 1419,4 & الأرز \\
\hline 5,74 & 329,8 & 323,1 & 319,3 & 345,6 & 332,0 & 329,2 & قصب السكر \\
\hline 5,20 & 298,9 & 269,7 & 275,6 & 293,4 & 369,2 & 286,7 & القطن \\
\hline 2,47 & 141,7 & 146,7 & 136,8 & 142,6 & 134,4 & 147,8 & الفــول الســوداني \\
\hline 1,20 & 69,2 & 71,6 & 77,1 & 73,9 & 63,8 & 59,6 & 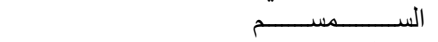 \\
\hline 0,49 & 28,3 & 28,8 & 31,9 & 36,5 & 21,8 & 22,4 & فــــول الصـــيا \\
\hline 0,27 & 15,8 & 17,3 & 14,6 & 15,4 & 16,3 & 15,2 & عبــاد الثــــــــس \\
\hline 9,03 & 519,0 & 536,7 & 509,4 & 514,9 & 540,0 & 493,8 & العلف الأخضر \\
\hline 2,36 & 135,5 & 125,7 & 133,2 & 141,1 & 143,8 & 133,7 & البطـــــــاطــــــــس \\
\hline 4,33 & 248,8 & 255,8 & 245,8 & 238,1 & 266,0 & 238,4 & 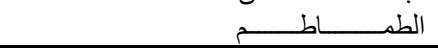 \\
\hline 100,00 & 5745,8 & 5825,7 & 5816,5 & 5933,0 & 5589,7 & 5564,2 & جملة الصيفي \\
\hline 71,69 & 261,7 & 298,5 & 267,4 & 287,3 & 239,0 & 216,2 & الذرة الثـاميــــة \\
\hline 13,99 & 51,1 & 60,5 & 38,3 & 42,4 & 62,2 & 51,9 & 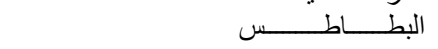 \\
\hline 14,32 & 52,3 & 54,1 & 58,3 & 52,2 & 48,1 & 48,7 & 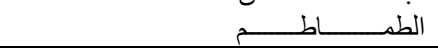 \\
\hline $\mathbf{1 0 0 , 0 0}$ & 365,0 & 413,1 & 364,0 & 381,9 & 349,4 & 316,9 & جملة النيلي \\
\hline \multirow[t]{3}{*}{100,00} & 12476,2 & 12705,2 & 12562,1 & 12706,4 & 12263,5 & 12143,9 & إجمالي أنشطة النموذج . \\
\hline & 15120,6 & 15643,0 & 15290 & 15104 & 14837 & 14729 & إجِمالي مساحة الجمهورية المحصولية \\
\hline & 82,5 & 81,2 & 82,2 & 84,1 & 82,7 & 82,4 & الجمالي أنثطة النموذج من إجمالي مساحة \\
\hline
\end{tabular}

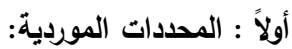

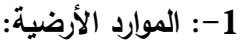

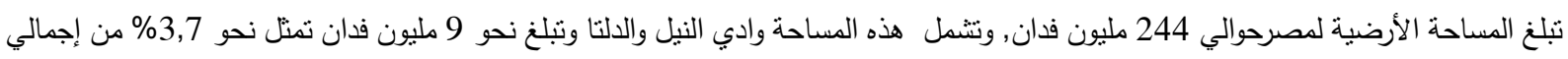

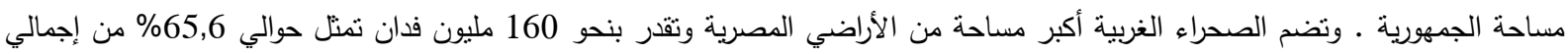
المساحة الكلية ـ أما الصحراء الثرقية فتبلغ مساحتها نحو 60 مليون فدان تمثل نحو 24,6\% من إجمالي المساحة الكلية ، بينما شبة جزيرة سيناء

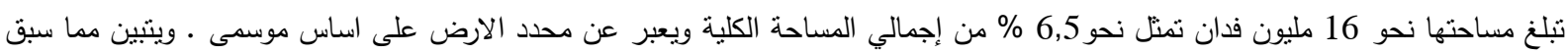

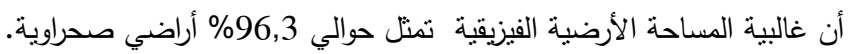

تطور مساحة الأراضي الزراعية والمحصولية: يوضح جدول رقم (2) إجمالي مساحة الزمام والمساحة المحصولية لكلاً من العروة الثنتوية والصيفية والنيلية والمعمرات خلال فترة الدراسة ( 2013-

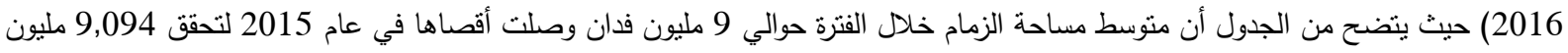

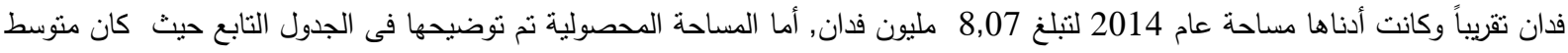

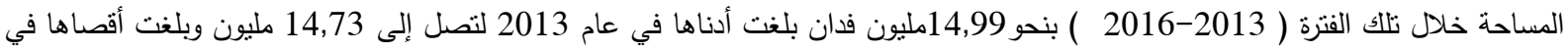
2016 لتحقق 15,29 مليون فدان وذلك برجع إلى زيادة التكثيف الحصصولي خلال نلك الفترة. 
جدول 2. إجمالي مساحة الزمام والمساحة المحصولية ( مليون فدان ) خلال الفترة ( 2013-2016)

\begin{tabular}{|c|c|c|c|c|c|c|c|}
\hline \multirow{2}{*}{ اجمالي مساحة الزمام } & \multicolumn{2}{|c|}{ مساحة الزمام } & \multicolumn{2}{|c|}{ المعدر ات } & \multicolumn{2}{|c|}{ المساحة الشتوية } & \multirow[t]{2}{*}{ السنوات } \\
\hline & أر اضي جديدة & أر اضي قديمة & أر اضي جديدة & أر اضي قديمة & أر اضي جديدة (2) & أر اضي قديمة & \\
\hline 8,949 & 2,767 & 6,182 & 1,26 & 0,884 & 1,507 & 5,298 & 2013 \\
\hline 8,907 & 2,83 & 6,077 & 1,32 & 0,867 & 1,51 & 5,21 & 2014 \\
\hline 9,094 & 2,94 & 6,154 & 1,33 & 0,874 & 1,61 & 5,28 & 2015 \\
\hline 9,07 & 2,92 & 6,15 & 1,3 & 0,86 & 1,62 & 5,29 & 2016 \\
\hline 9,00 & 2,86 & 6,14 & 1,30 & 0,87 & 1,58 & 5,30 & المتوسط \\
\hline
\end{tabular}

(1) مساحة الزمام تساوى إجمالي مساحة المحاصيل الثتوية بدون برسيم التحريش مضافا اليها مساحة المعمرات

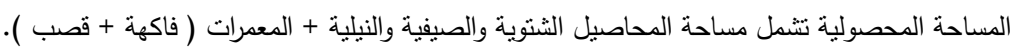

تابع جدول 2. إجمالي مساحة الزمام والمساحة المحصولية (مليون فدان ) خلال الفترة ( 2013-2016)

\begin{tabular}{|c|c|c|c|c|c|}
\hline \multirow{2}{*}{ إجمالي المساحة المحصولية } & \multicolumn{2}{|c|}{ المساحة المحصولية(2) } & \multicolumn{2}{|c|}{ المحاصيل الصيفية و النيلية } & \multirow{2}{*}{ 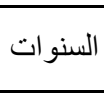 } \\
\hline & أر اضي جديدة & أر اضي قديمة & أر اضي جديدة & أر اضي قديمة & \\
\hline 14,73 & 3,21 & 11,52 & 0,44 & 5,34 & 2013 \\
\hline 14,84 & 3,28 & 11,55 & 0,45 & 5,48 & 2014 \\
\hline 15,1 & 3,4 & 11,71 & 0,46 & 5,55 & 2015 \\
\hline 15,29 & 3,39 & 11,9 & 0,47 & 5,75 & 2016 \\
\hline 14,99 & 3,32 & 11,67 & 5,45 & 5,53 & المتوسط \\
\hline
\end{tabular}

المصدر : وزارة الزراعة وإستصلاح الأراضي- قطاع الشئون الإقتصادية- نشرة الإحصاءات الزراعية أعداد متفرقة.

2-2

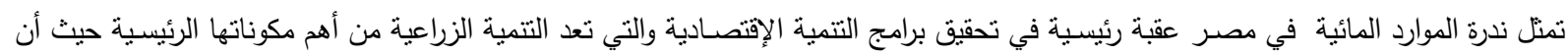

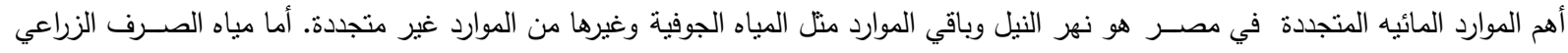

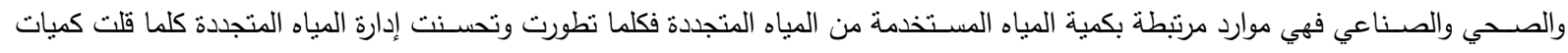
المياه الناتجة من الصـرف بأنواعه حتى تصـل لحد الندرة لذا تم تحديد قيد المورد المائي بالتزامن مع تطور العجز المائي المتوقع والذي سـوف يكون

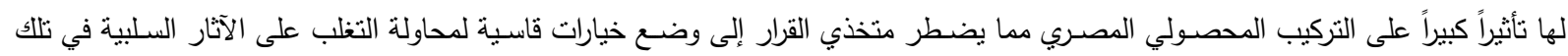

المرحلة.

لذا فى خلاد هذه الدراسـة نم وضـع ثلاث سيناريوهات إفتراضية للعجز المائي المتوقع للموارد المائية النيلية بالإضـافة لمياه الصـرف الزراعي وذلك ألكاه لإرتباط كمية مياه الصـرف بكميات المياه المضـافة لري المحاصـيل من مياه النيل ، حيث قدر أن يصـل هذا العجز وفقا للسـيناريو الأول إلى 10

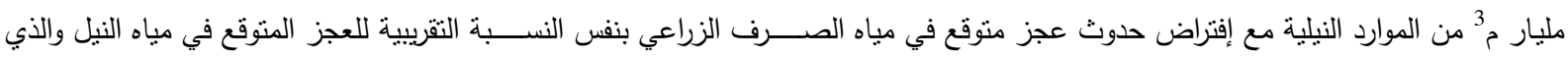

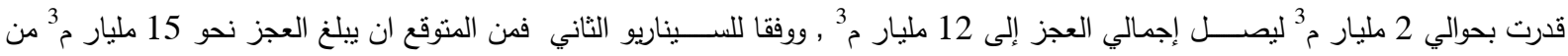
الموارد النيلية مع إفتراض حدوث عجز متوقع في مياه الصـرف الزراعي بنفس النسـبة التقربيية للعجز المتوقع في مياه النيل والذي قدرت بحوالي 3

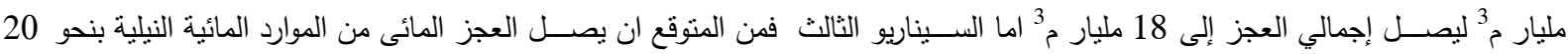

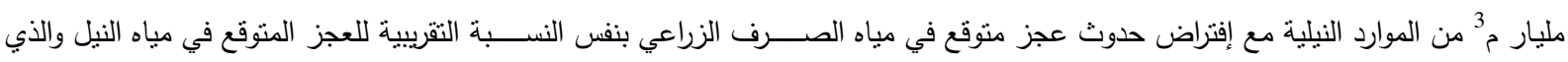

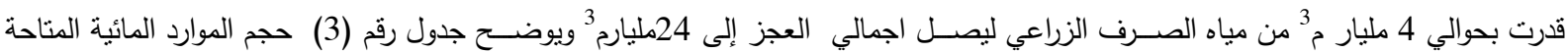
وإستخداماتها المختلفة خلال الفترة من من مياد من 2013 - 2016.

جدول رقم 3. حجم الموارد المائية المتاحة في مصر من مصادرها وإستخداماتها المختلفة خلال الفترة (2013-2016).

\begin{tabular}{|c|c|c|c|c|c|}
\hline$\%$ & المقدار مليار & الاستخدامات المائية & $\%$ & كمية المياه & مختلف المصارد المائية من \\
\hline 85,7 & 61,5 & الزراعة & 74,5 & 55,5 & حصة مياه نهر النيل \\
\hline 9,7 & 9,7 & الشرب و الاستخدامات الصحية & 12,3 & 9,17 & مياه الصرف الزر اعي \\
\hline 1,9 & 1,2 & الصناعة & 10,1 & 7,5 & المياه الجوفية " \\
\hline 3 & 2,2 & الفاقد بالبخر & 1,7 & 1,3 & مياه الصرف الصحي \\
\hline 0 & 0 & - & 1,3 & 0,97 & 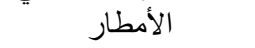 \\
\hline 0 & 0 & - & 0,1 & 0,06 & تحلية مياه البحر \\
\hline 100 & 74,5 & & 100,0 & 74,5 & الإجمالى \\
\hline
\end{tabular}

المصدر : الجهاز المركزي للتعبئة العامة والإحصاء - الكتاب الإحصائي السنوي أعداد متفرقة. 
ثانياً :القيود التنظيمية:

تحددت القيود التنظيمية لسـيناريوهات الدراســة وفقا لمدى التغيرات المؤثرة في كمية المياه المقرة لكل نموذج على حدة ، حيث إن إنخفاض كميات

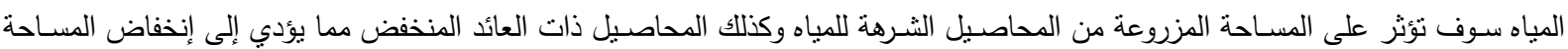
المحصولية كنتيجة حتمية للعجز المائي المتوقع وعلى ذلك فإن القيود التنظيمية سنكون كما يلي.

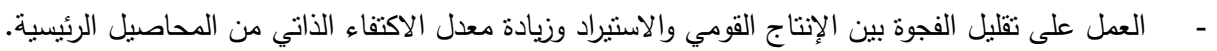

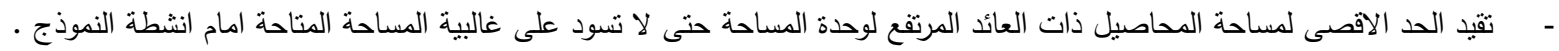
- خفض مسـاحة المحاصـيل الثـرهة في إسـتخدامها المائي و المحاصيل ذات العائد المنخفض والحفاظ على مسـاحة المحاصيل ذات العائد المادي المرتفع و الإحتياجات المائية المنخفضـة طبقا للموارد المائية المتاحة للنموذج لكل سـيناريو من السـيناريوهات الثثلاث على سـبيل المثال محصول الأرز حيث قامت الدولة بإصدار القرارات الملزمة بخفض مساحة الأرز من 1450 ألف فدان تقريبا إلى أقل من 750 ألف هن فدان, كذلك إتجاه الدولة لإستبدال زراعة قصب السكر بمحاصبل أخرى أقل إستهلاكاً للماء لذا إرتكزت السيناريوهات المقترحة والتي سيتم

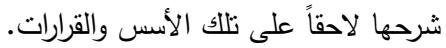
- الحفاظ على مساحة باقي المحاصيل الأخرى وألا تزيد عن الحد الأقصى لمتوسط الفترة (2013-2017).

(د) مصفوفة المعاملات الفنية:

حسبت المعاملات الفنية لنموذج الدراسـة من مصادر منعددة, فالمعاملات الفنية الخاصـة بكمية الموارد أو المدخلات المستخدمة لإنتاج فدان في أي

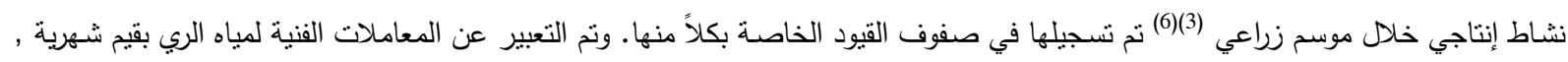
وموسـية أما المعاملات الخاصـة بصـافي العائد الفداني لمياه الري وهي الإنتاج ( رئيسي- ثانوي) وأسـعار المخرجات , وأسعار مستلزمات الإنتاج

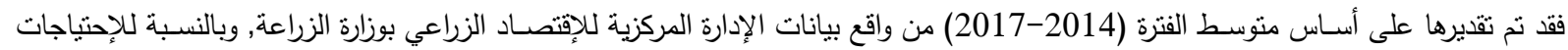
المائية المحصولية فتم تقديرها وفقاً لبيانات وزارة الموارد المائية والري كما هو مبين بجدول الدراسة رقم (4). جدول رقم 4. صافي عائد وحدة المياه( جنية / م³ ) لأهم المحاصيل الزراعية وفقاً للأسعار المالية خلال الفترة (2014- 2017)

\begin{tabular}{|c|c|c|c|c|c|c|c|c|c|}
\hline (جنية العيأد على & 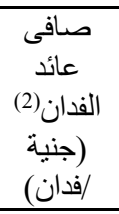 & 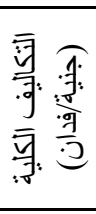 & 永年: & 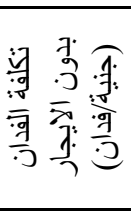 & جملة إيراد & المحضمول & المحصول & الإحتياجا & المحصول \\
\hline & & & & & & & & \multicolumn{2}{|c|}{ المحاصيل الثنوية } \\
\hline 2,45 & 6484 & 5706 & 2013 & 3693 & 12190 & 2028 & 10163 & 2651 & القــح \\
\hline 1,95 & 4593 & 3942 & 1425 & 2517 & 8535 & 1320 & 7215 & 2350 & الثـعير \\
\hline 3,13 & 11781 & 3723 & 2041 & 1682 & 15504 & 0 & 15504 & 3766 & المستديم \\
\hline 5,71 & 6654 & 2480 & 1601 & 879 & 9134 & 0 & 9134 & 1166 & تحريش \\
\hline 1,87 & 4433 & 5345 & 1943 & 3402 & 9778 & 1086 & 8692 & 2369 & البلدى الفول \\
\hline 3,39 & 4804 & 4558 & 1575 & 2983 & 9362 & 544 & 8818 & 1417 & العدس \\
\hline 2,30 & 4519 & 4914 & 1423 & 3491 & 9433 & 857 & 8575 & 1962 & الحمص \\
\hline 1,44 & 4887 & 5396 & 1873 & 3523 & 10283 & 1191 & 9093 & 3395 & بنجـــر \\
\hline 2,50 & 5741 & 4232 & 1643 & 2589 & 9973 & 5863 & 4110 & 2292 & الكـنان \\
\hline 6,37 & 11793 & 4500 & 1196 & 3304 & 16293 & 0 & 16293 & 1850 & البصـل \\
\hline 5,16 & 11425 & 6270 & 1329 & 4941 & 17695 & 0 & 17695 & 2212 & 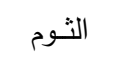 \\
\hline 9,51 & 21824 & 6044 & 1341 & 4703 & 27868 & 0 & 27868 & 2294 & الطمـاطم \\
\hline 5,59 & 12166 & 6175 & 1531 & 4644 & 18341 & 0 & 18341 & 2175 & البطاطس \\
\hline
\end{tabular}




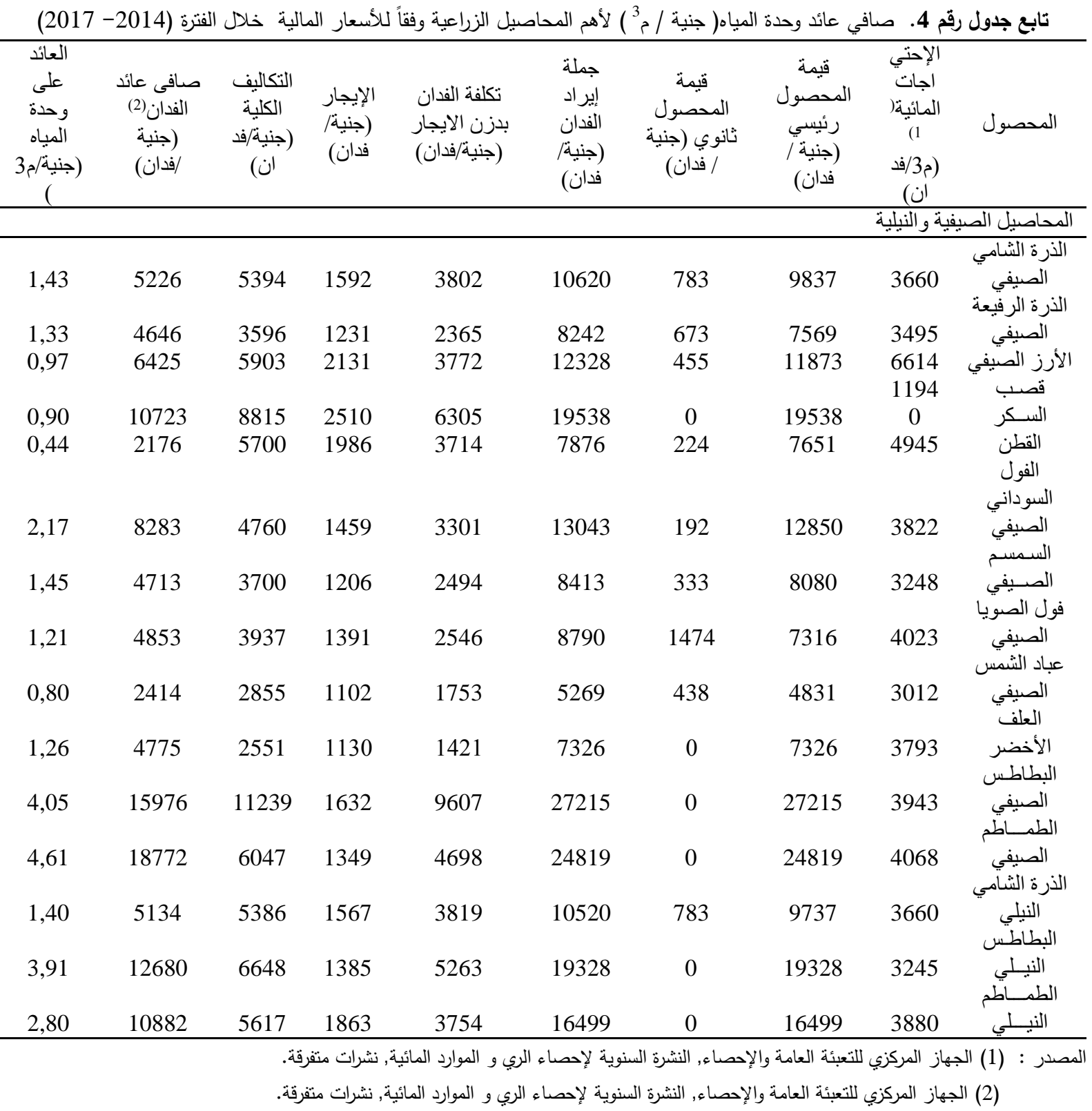

نتائج الدراسة:

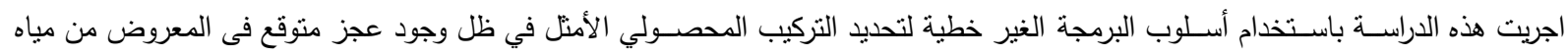

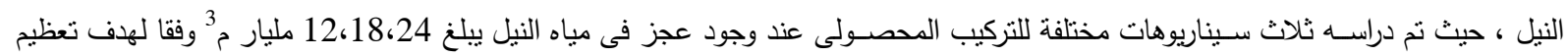

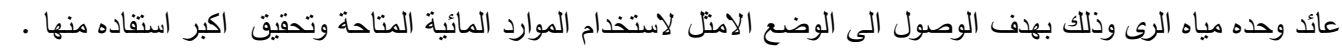

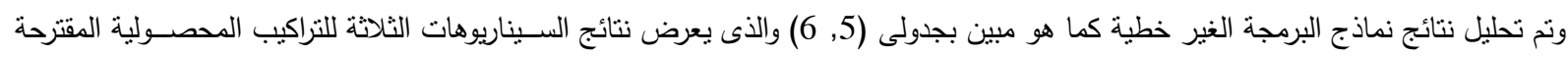

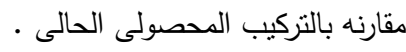
السيناريو الأول : التركيب المحصولي الأمثل في ظل وجود عجز مائي 12 مليار متر مكع.

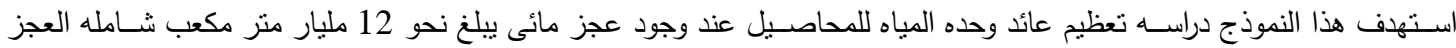
المائى المتوقع من الموارد النيليه ومياه الصرف الزراعى. بالمقارنه للتركيب المحصولى المقترح الذى يتضمن 28 محصولا بالتركيب المحصسولي

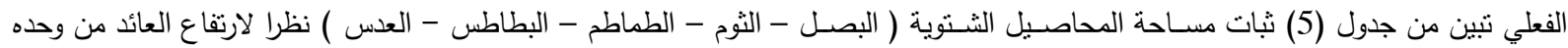

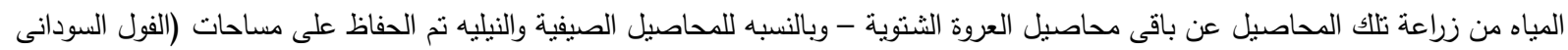
- السمسم - البطاطس -الطماطم - عباد الثمس ) نظرا لارتفاع عائد وحدة المياه من نلك المحاصيل عن باقى المحاصيل الصيفية والنيليه فى الئ حين انخفت المساحات المزروعة من المحاصيل الثنوية ( القمح - الثتعير - البرسيم المستديم - برسيم التحريش - الفول البلاى - حمص - 


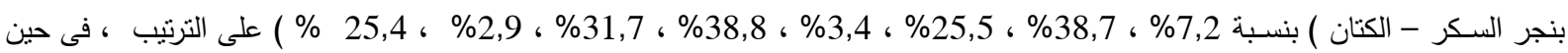

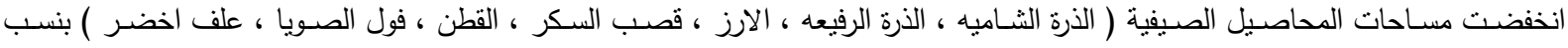

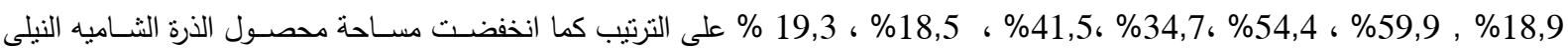
بمعد 17\% وييين جدول (5) صافى عائد البديل الاول ويبلغ 77,1 مليار جنيه ويقل عن التركيب الدحصولى الفعلى والذى يقدر بنحو 93,6 مليار

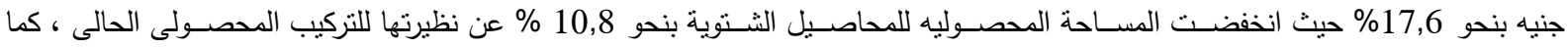

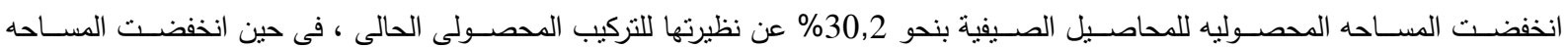
الدحصوليه للمحاصيل النيليه ( الذرة الثشاميه النيلى ) عن نظيرتها بنسبه 12,2\% عن التزكيب المحصولى الفعلى .

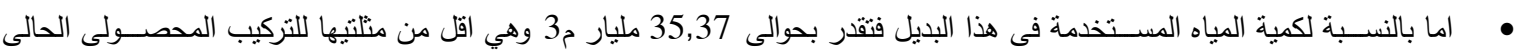

بحوالى 12 مليار م3 والتى تبلغ 47,37 مليار م3 اى بنسبه تصل بنحو 25,3 \%من جملة الاحتباجات المائية للتركيب الحالى .

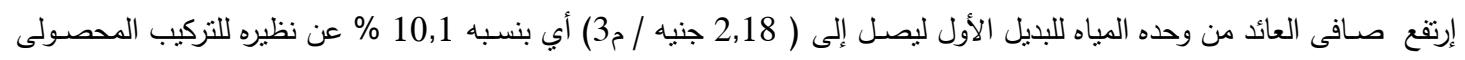
الفعلى نظراً لذفض المساحات المزروعة من المحاصيل ذات الاستهلاك المائي المرتفع.

جدول رقم 5 ـ نتائج السيناريوهات المختلفة للتركيب المحصولي الثنتوي مقارنة بالتركيب المحصول الحالي خلال الفترة 2013-2017 )

\begin{tabular}{|c|c|c|c|c|c|c|c|}
\hline \multicolumn{2}{|c|}{ 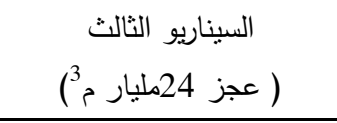 } & \multicolumn{2}{|c|}{ السيناريو الثاني ( عجز 18مليار } & \multicolumn{2}{|c|}{$\begin{array}{l}\text { السيناريو الأول (عجز } 12 \\
\text { 1مليار مج) }\end{array}$} & \multirow{3}{*}{ المساحة ألف } & \multirow{3}{*}{ الدحصول } \\
\hline نسبة التغير & المساحة ألف & نسبة التغير & المساحة ألف & نسبة التغير & المساحة ألف & & \\
\hline$\%$ & فدان & $\%$ & فدان & $\%$ & فدان & & \\
\hline$-22,5$ & 2657,3 & $-20,7$ & 2718,6 & $-7,2$ & 3183,3 & 3429,8 & القــح \\
\hline$-68,2$ & 45,1 & $-68,2$ & 45,1 & $-38,7$ & 87,1 & 142,0 & الثشعير \\
\hline$-49,4$ & 627,1 & $-48,4$ & 639,8 & $-25,5$ & 923,6 & 1240,1 & البرسيم المستديم \\
\hline$-9,1$ & 305,1 & $-4,8$ & 319,7 & $-3,4$ & 324,3 & 335,8 & برسيم التحريش \\
\hline$-38,8$ & 61,3 & $-38,8$ & 61,3 & $-38,8$ & 61,3 & 100,1 & الفول البلدي \\
\hline 0,0 & 1,1 & 0,0 & 1,1 & 0,0 & 1,1 & 1,1 & العدس \\
\hline$-20,3$ & 1,1 & $-31,0$ & 1,0 & $-31,0$ & 1,0 & 1,4 & الحمص \\
\hline$-35,8$ & 325,2 & $-13,7$ & 437,0 & $-2,9$ & 491,9 & 506,6 & بنجر السكر \\
\hline 0,0 & 5,9 & $-36,9$ & 3,7 & $-25,4$ & 4,4 & 5,9 & الكتان \\
\hline 0,0 & 158,1 & 0,0 & 158,1 & 0,0 & 158,1 & 158,1 & البصل \\
\hline 0,0 & 26,1 & 0,0 & 26,1 & 0,0 & 26,1 & 26,1 & الثوم \\
\hline 0,0 & 194,8 & 0,0 & 194,8 & 0,0 & 194,8 & 194,8 & طمـاطح \\
\hline 0,0 & 223,6 & 0,0 & 223,6 & 0,0 & 223,6 & 223,6 & بطاطس \\
\hline$-27,2$ & 4631,7 & $-24,1$ & 4829,7 & $-10,8$ & 5680,4 & 6365,2 & جملة الثتوي \\
\hline
\end{tabular}

winqsb المصدر : نتائج تحليل البرمجة متعددة الأهداف 
ويتطبيق المعادلة على محصول القمح كمثال للمحاصيل الثتوية نجد أنه:

1- 1 1 السيناريو الأول عند عجز مائي 12 مليارم 3

$\operatorname{Max} z=\Sigma_{1}\left(P_{J K} Y_{J K}-C_{J K}\right) X_{J K}-\Sigma V_{J K}$

Z = المساحة المزروعة من القمح ألف فدان 3183,3 (( الرئيسي 18,82 أردب + ثنانوي 11,5 حمل نبن *سعر وحدة المحصول جنيه الرئيسي 540 + الثانوي 183 جنيه) - التكاليف الاستثمارية 2013)) صافي العائد مخصوما منه التكاليف الثابتة

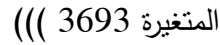
6484= 3183,3 = Z

2- السيناريو الثاني عند عجز مائي 18 مليارم3 3 6484= 2718,6 = Z

3- السيناريو الأول عند عجز مائي 24 مليارم3 3 6484= 2657,3 = Z

تابع جلول رقم 5. مقــارنة نتائج السيناريوهات المختلفة للتركــيب المحصولي الصيفي والنيلي مقارنة بالتركيب المحصول الحالي خلال الفـترة ( (2017-2013

\begin{tabular}{|c|c|c|c|c|c|c|c|}
\hline \multicolumn{2}{|c|}{ ( عجز مائي 24مليار م³) } & \multicolumn{2}{|c|}{ (عجز مائي 18مليار م³ الثاني ) } & \multicolumn{2}{|c|}{ ( عجزمائيناريو الأوليار م33 ) } & الفعلي & \multirow{2}{*}{ المحصول } \\
\hline نسبة التغير & فاحة ألف & نسبة التغير & فاحة ألف & التغبية & المساحة ألف & قاحة ألف & \\
\hline$-57,8$ & 925,6 & $-23,8$ & 1672,5 & $-18,9$ & 1781,9 & 2195,9 & الذرة الذرة الذيـــــة \\
\hline$-74,6$ & 88,3 & $-65,0$ & 121,5 & $-59,9$ & 139,3 & 347,3 & الرفيعـــــــة \\
\hline$-93,3$ & 94,3 & $-77,0$ & 326,3 & $-54,4$ & 646,1 & 1415,8 & الأرز \\
\hline$-52,7$ & 156,1 & $-37,9$ & 204,7 & $-34,7$ & 215,3 & 329,8 & قصب السكر \\
\hline$-61,5$ & 115,1 & $-58,7$ & 123,5 & $-41,5$ & 174,9 & 298,9 & الفــن \\
\hline 0,0 & 141,7 & 0,0 & 141,7 & 0,0 & 141,7 & 141,7 & السـودانى \\
\hline 0,0 & 69,2 & 0,0 & 69,2 & 0,0 & 69,2 & 69,2 & 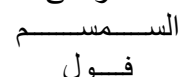 \\
\hline$-50,3$ & 14,0 & $-29,6$ & 19,9 & $-18,5$ & 23,0 & 28,3 & الصـــــــيا \\
\hline$-4,0$ & 15,1 & 0,0 & 15,7 & 0,0 & 15,7 & 15,7 & الثــــــــس \\
\hline$-43,9$ & 291,2 & $-30,8$ & 359,0 & $-19,3$ & 419,0 & 519,0 & العلف الأخضر \\
\hline 0,0 & 135,5 & 0,0 & 135,5 & 0,0 & 135,5 & 135,5 & البطـــاطـــــــس \\
\hline 0,0 & 248,8 & 0,0 & 248,8 & 0,0 & 248,8 & 248,8 & الطـــــــاطـــــم \\
\hline$-60,1$ & 2295,0 & $-40,2$ & 3438,3 & $-30,2$ & 4010,5 & 5746,0 & جملة الصيفي \\
\hline$-50,6$ & 129,3 & $-38,8$ & 160,1 & $-17,0$ & 217,3 & 261,7 & الذرة الشـاميـــــة \\
\hline 0,0 & 51,1 & 0,0 & 51,1 & 0,0 & 51,1 & 51,1 & البط لــــــاطــــس \\
\hline 0,0 & 52,3 & 0,0 & 52,3 & 0,0 & 52,3 & 52,3 & الطمــــــاطـــــم \\
\hline$-36,3$ & 232,7 & $-27,8$ & 263,5 & $-12,2$ & 320,7 & 365,2 & جملة النيلي ' \\
\hline$-40,3$ & 7452,6 & $-31,6$ & 8531,6 & $-19,8$ & 10011,6 & 12476,4 & الإجمالي \\
\hline
\end{tabular}


ويتطبيق المعادلة على محصول الذرة الثامية كمثال للمحاصيل الصيفيه نجد أنه:

$$
\text { 1- 1 1 السيناريو الأول عند عجز مائي } 12 \text { مليارم } 3
$$

$\operatorname{Max} z=\Sigma_{1}\left(P_{J K} Y_{J K}-C_{J K}\right) X_{J K}-\Sigma V_{J K}$

Z = المساحة المزروعة من الذرة الثامية ألف فدان 1781,9 (( الرئيسي 22,41 أردب + ثانوي 10,58 حمل *سعر وحدة المحصول جنيه الرئيسي 439 + الثانوي 74 جنيه) - التكاليف الإستثمارية 1562)) صافي العائد مخصوما منه التكاليف الثابتة 9028 - التكاليف المتغيرة 9,31=5226*1781,9=Z

2- السيناريو الثاني عند عجز 18 مليارم3. 8,74 =5226*1672,5 = Z

3- 3- السيناريو الثالث عند عجز 24 مليارم3. 4,84 =5226*925,6 = Z

جدول رقم 6. المؤشرات الاقتصادية للتركيب المحصولي المقترح مقارنة بالتركيب المحصول الحالي خلا الفترة (2017-2013)

\begin{tabular}{|c|c|c|c|c|c|c|}
\hline 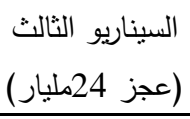 & (عجز 18 السيناريو الثاني & 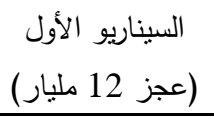 & التركيب المحصولي & الوحـــة & البيـــــــــان & r \\
\hline 4631,7 & 4829,7 & 5680,4 & 6365,2 & ألف فدان & إجمالي المساحة المزروعة & 1 \\
\hline 2295 & 3438,3 & 4010 & 5746 & ألف فدان & إجمالي المساحة المزروعة & \\
\hline 232,7 & 263,5 & 320,7 & 365,2 & ألف فدان & إجمالي المساحة المزروعة & \\
\hline 7452,6 & 8531,6 & 10011,6 & 12476,4 & ألف فدان & المحصولية لأنشطة & 2 \\
\hline 23,37 & 29,37 & 35,37 & 47,37 & مليار م3 & إجمالي كميات مياه الري & 3 \\
\hline 58,3 & 66,3 & 77,1 & 93,6 & مليار جنيه & إجمالي صافي العائد & 4 \\
\hline 2,49 & 2,26 & 2,18 & 1,98 & جنيه/ה 3 & صافي عائد وحدة المياه & 5 \\
\hline
\end{tabular}

السيناريو الثاني : التركيب المحصولي الأمثل في ظل وجود عجز مائي 18 مليار متر مكب.

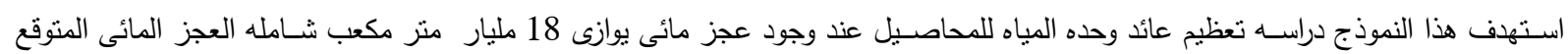

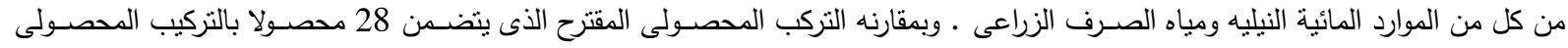

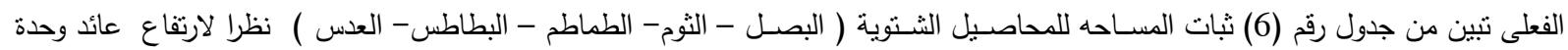
المياه لتللك المحاصيل عن نظيرتها من باقى محاصيل العروة الشتوية وبالنسبة للمحاصيل الصيفية والنيليه تم الحفاظ على مساحة ( الفول سودانى - السـمسـم -عباد الثـمس - البطاطس - الطماطم ) كما هى دون تغيير نظرا لارتفاع عائد وحدة المياه من تللك المحاصـيل عن باقى المحاصـيل الصيفية والنيليه فى حين انخفضت المساحات المنزرعة من المحاصيل الثـتوية ( القمح - الثنعير - البرسيم المستديم - برسيم التحريش - الفول

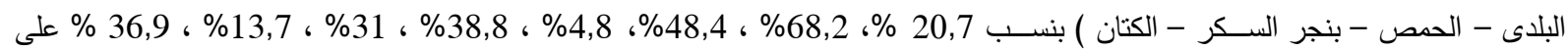
النرتيب ، فى حين انخفضـت مسـاحات المحاصـيل الصـيفية ( الذرة الثـامية - الذرة الرفيعة - الارز - قصـب السـكر - القطن - فول الصـويا -

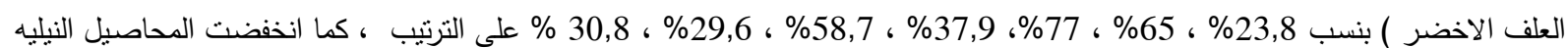
( الذرة الثامية ) بنسبه 38,8 \% 


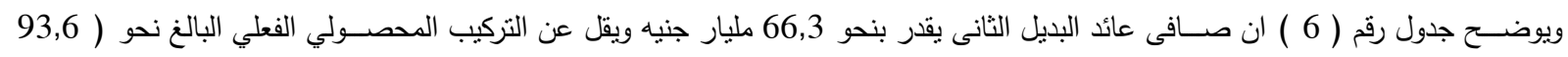

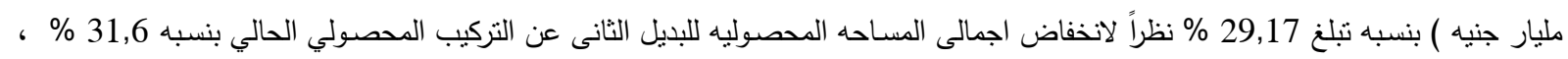
حيث انخفضت المساحة المحصوليه للمحاصيل الثنتوية بنسبه 24,3 \% عن نظيرتها للتركيب المحصولى الحالى كما انخفضت مساحة المحاصيل الصيفية للبديل الثانى بنسبة 40,2 \% عن نظيرتها للنزكيب المحصولى الحالى فى حين انخفضت مسـاحة المحاصيل النيليه للبديل الثانى بنسبه تبلغ 27,8 \% عن نظيرتها للتركيب المحصولى الفعلى . لإنيل

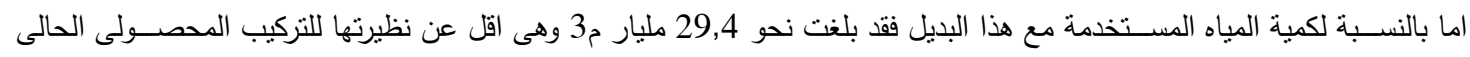
بنحو 18 مليار م3 مياه اى بنسبه تقل نحو 38\% عن الاحتياجات المائية للتركيب المحصولى الفعلى .

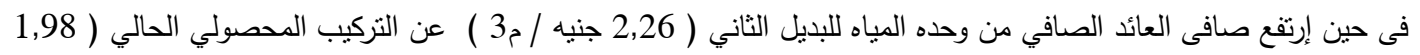

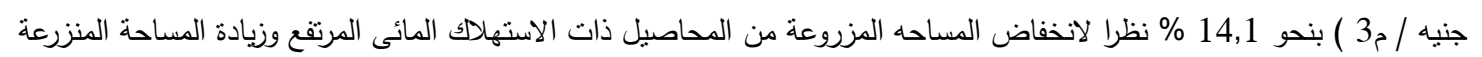

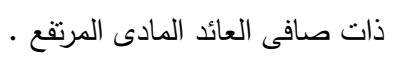

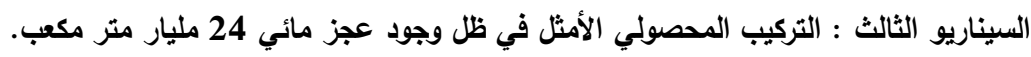

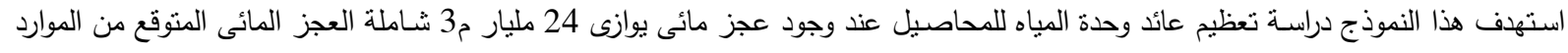

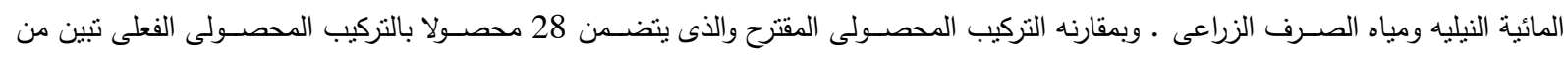

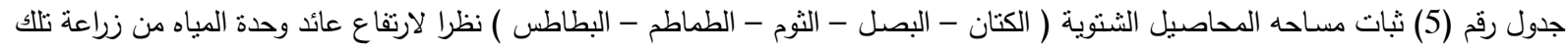

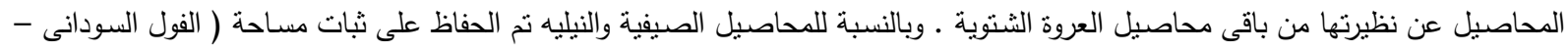

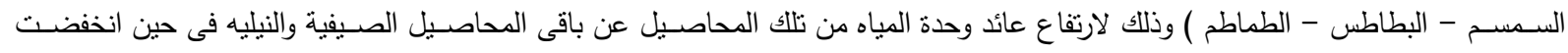

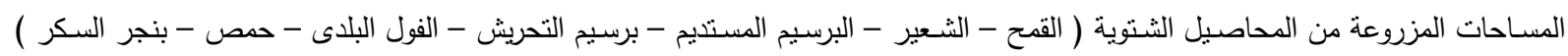

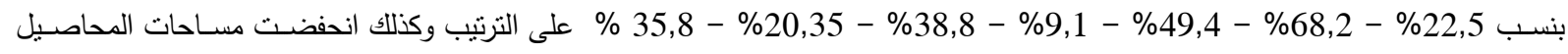

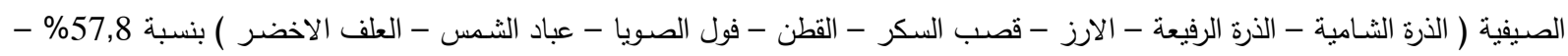

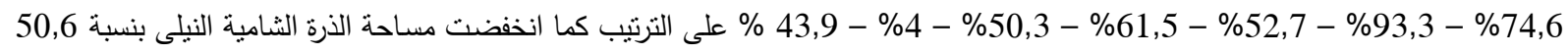

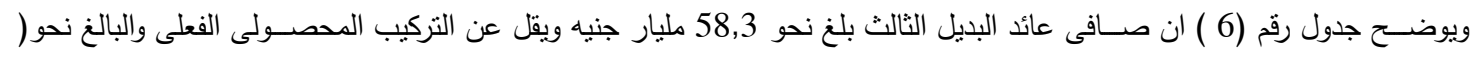

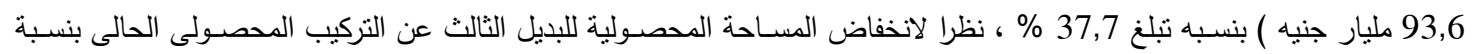

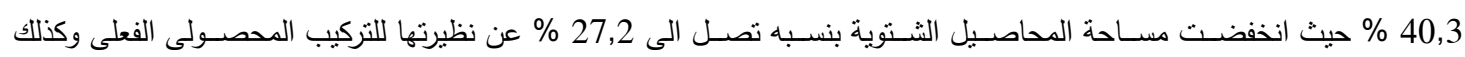
انخفضت مسـاحة المحاصيل الصيفية للبديل الثالث بنحو 60,1 عن نظيرتها للتركيب المحصولى الفعلى فى حين انخفضت مسـاحة

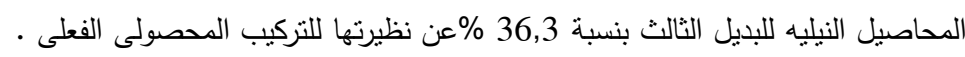

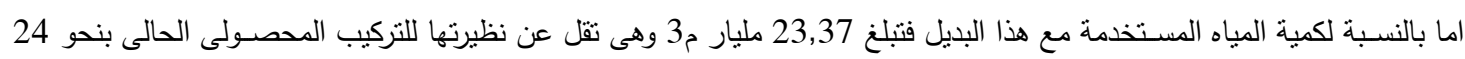

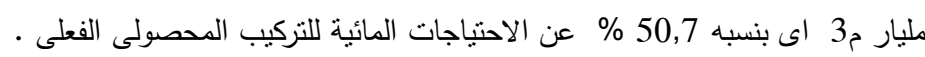

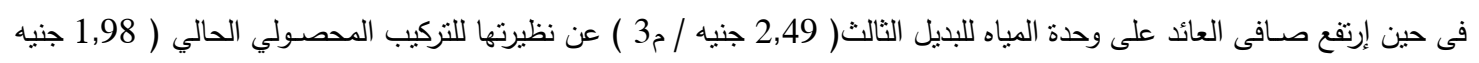

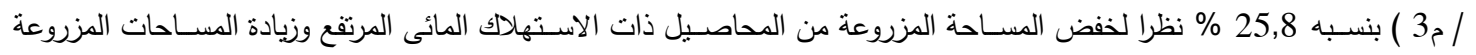
بالمحاصيل ذات صافى العائد المرتفع.

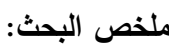

تتعرض الموارد المائية المصرية للنقص مستقبلا لما تمر به المنطقة من تغيرات مناخية وإقليمية وسياسية تؤثر بالتبعية على حصة

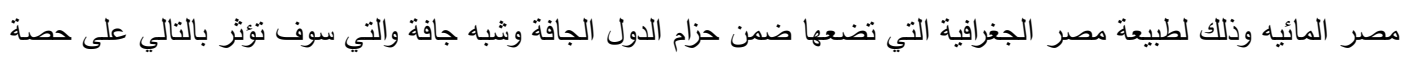
المياه المخصصة للزراعة والتي تصل إلى 61,5 وتمثل حوالي أكثر من 85\% من إجمالي الموارد المائية والبالغة حوالي 74,4 ملئي التيار

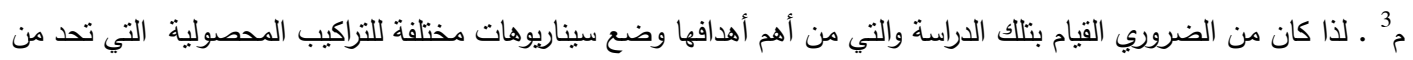

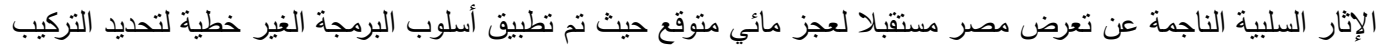

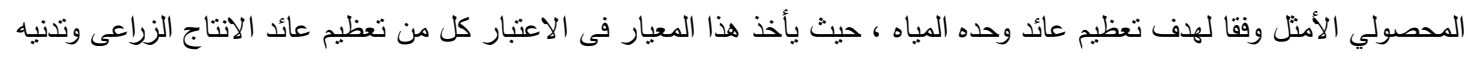

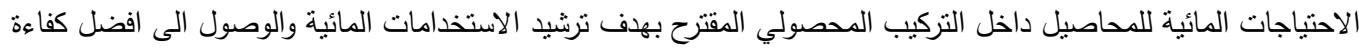

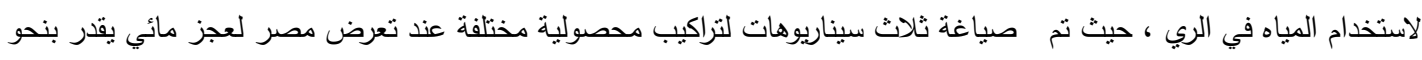


12 أو 18 أو 24 مليار متر مكعب مياه شامله كلا من الموارد النيلية ومياه الصرف الزراعي ومن خلال الدراسة تبين توقع حدوث

- ضـرورة تثتيت مسـاحة المحاصـيل ذات الاسـتهالاك المائى المرتفع والعائد المادى المنخفض مثل الارز وقصـب السـكر وغيرها من المحاصيل والتوجه نحو زراعة المحاصيل ذات العائد المرتفع لوحدة المياه .

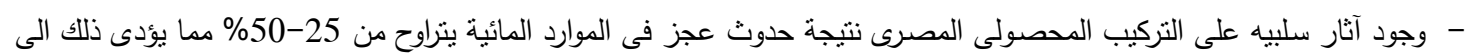
خفض المسـاحة المنزرعة من المحاصـيل الثـتوية والصـيفية والنيلية ومن ثم على خفض المســاحة المحصـولية الاجماليه بنسـبة نتراوح من20-40 \% الذي يؤدى الى نقص عائدالانتاج الزراعى الاجمالى بنحو 18-38\% وهذا يحذو بنا الى اتخاذ الاجراءات اللازمة للحد

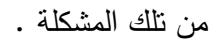

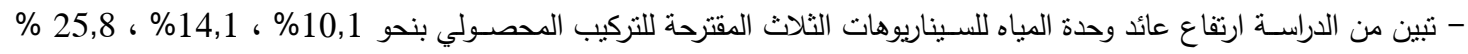

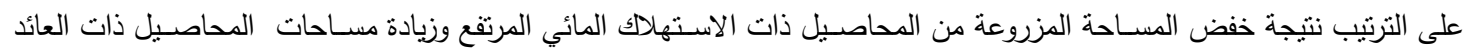
المادي المرتفع. 1- ضـــرورة إتخاذ التدابير اللازمة لإعادة تطبيق الدورة الزراعية على مختلف مناطق الجمهورية التي بدورها تمكن الدولة من تتفيذ التراكيب المحصولية التي تحقق أعلى عائد ممكن بإستخدام أقل كميات مياه ممكنه.

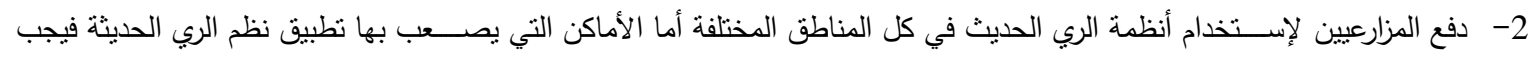
إلزام المزارعيين بإستخدام نظم الري المطورة بنلك المناطق.

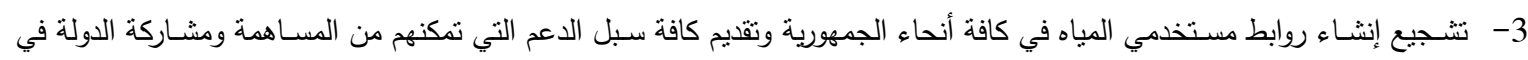
تتفيذ نوجهاتها عن طريق الاستغلال الأمنل للموارد المائية.

4- التوسع في زراعة المحاصيل ذات الاحتباجات المائية المنخفضة والحد من زراعة المحاصيل ذات الاستهلاك المائي المرتفع.

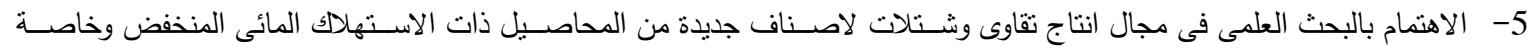
محاصيل الارز وقصب السكر - الموز ، وكذلك انتاج اصناف ذات قدرة عالية على تحمل الملوحة الزائدة . 6- استخدام مياه هامشية النوعية للرى لتعويض العجز المنوقع فى مياه النيل .

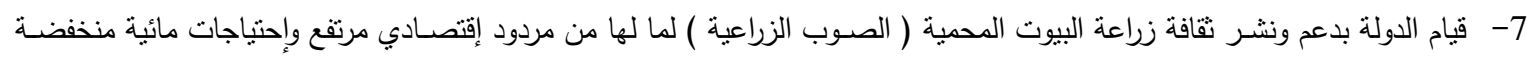
لنفس المحصول المزروع مقارنة بالزراعة المفتوحة. 8- السـعي للحصـول على إيرادات أكبر من المياه عن طريق إسـنقطاب الفواقد في منطقة أعالي النيل مثال: قناة جونجلى ومشـروعات بحر الغزال ومشار وأوكابو أبوكو.

(1) أحمد أحمد جويلي ( دكتور), التتمية الإقتصادية الزراعية في ج•م•ع, المركز القومي للبحوث الإجتماعية الجنائية, مؤتمر الإجنماع والتتمية في مصر , مايو 1983م.

(2) أحمد حنفي عبد الرحمن ، الاستخدام الاقتصادي الأمثل للموارد المائية المتاحة بمحافظة الوادي الجديد ، رسالة ماجستير ، قسم الاقتصاد

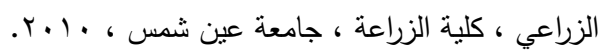
(3) الجهاز المركزي للتعبئة العامة والإحصاء- نشرة السنوية للري والموارد المائية أعداد متفرقة للسنوات 2013 - 2017.

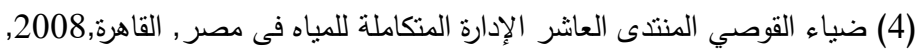

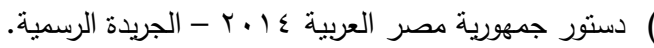

(6) وزارة الزراعة وإستصلاح الأراضي، قطاع الثئون الإقتصادية "نشرة الإحصاءات الزراعية" أعداد متفرقة للسنوات 2013 - 2017,

\section{ثانياً : مراجع باللغة الانجليزية:}

(7)- Huang G., Loucks D. "An Inexact Two-Stage Stochastic Programming Model for Water Resources Management Under Uncertainty" Civil Engineering Environmental Systems, vol. 17,2000:95-18, 
(8)-Kall, P. \& Mayer, J. "Stochastic Linear Programming: Models, Theory and Computation" Springer International Series in Operations Research and Management Science, Norwell, MA: Kluwer Academic Publishers, 2005.

\title{
The Suggested Cropping Pattern of The under risk water deficit Expected in Egypt
}

\author{
Yasser, M, Ahmed; Hassan, A, Abd Elreheem \\ Water Management Research Institute, National Water Research Center, Delta Barrages. Egypt
}

\section{Summary}

Egypt's water resources will be reduced in the future because of the region's climate, regional and political changes, which will consequently affect Egypt's Water allocated to agriculture, which reaches 61.5 and accounts for about $85 \%$ of the total water resources of 74.4 billion $\mathrm{m} 3$. Therefore, it was necessary to carry out this study, one of the most important objectives of which is to develop different scenarios for crop structures that reduce the negative effects resulting from the future exposure of Egypt to water shortage expected. The non-linear programming method was applied to determine the optimum crop of reach the best efficiency water use in irrigation, where three scenarios have been formulated for different crop structures when Egypt is exposed to water deficit estimated at 12,18 or 24 billion cubic meters of water, including both Nile resources and agricultural wastewater. omposition according to the objective of maximizing the yield of the water unit.

The presence of negative effects on the Egyptian cropping structure as a result of a deficit in water resources ranging from $25-50 \%$, which leads to a reduction of the cultivated area of winter, summer and Nile crops, which affects the reduction of total crop area by $20-40 \%$, which leads to a decrease in yield of agricultural production The total is about $18-38 \%$ and this leads us to take the necessary measures to reduce that problem. 